\title{
ANÁLISE QUALITATIVA DA PASSAGEM DO CLORO PELO PROCESSO DE ACIARIA ELÉTRICA E SUA DISTRIBUIÇÃO NAS EMISSÕES E POEIRAS*
}

\author{
Pedro Jorge Walburga Keglevich de Buzin ${ }^{1}$ \\ Nestor Cezar Heck ${ }^{2}$ \\ Antônio Cezar Faria Vilela ${ }^{3}$
}

\begin{abstract}
Resumo
O cloro no processo de aciaria elétrica tem sua principal fonte nas contaminações de origem orgânica existentes nas matérias-primas usualmente empregadas, principalmente na sucata. Apesar dos atuais níveis de cloro não perturbarem a fabricação do aço nas mini-mills, a presença deste elemento e dos compostos por ele gerados tem influência deletéria nos aspectos laborais, ambientais, de manutenção das instalações e na reciclagem das poeiras de aciaria. Neste trabalho, com base na integração de dados da literatura, da indústria e de propriedades físicas, químicas e termodinâmicas das substâncias envolvidas é feita uma avaliação qualitativa da passagem do cloro na aciaria elétrica e sua distribuição nas diversas correntes de massa de saída do processo. Foi concluído que a maior parte do cloro que entra no FEA deixa o sistema concentrando-se nas emissões do processo, principalmente nas poeiras de aciaria, sob a forma de cloretos alcalinos.
\end{abstract}

Palavras-chave: Cloro; Aciaria elétrica; Reciclagem; Meio ambiente.

\section{QUALITATIVE ANALYSIS OF THE CHLORINE PATH THROUGH ELECTRIC STEELMAKING PROCESS AND ITS DISTRIBUTION IN EMISSIONS AND EAF DUST}

\begin{abstract}
Chlorine in the electric steelmaking process has its main source from existing organic contaminants in commonly used raw materials, especially in scrap. Although the current levels of chlorine do not disturb the steel production in mini-mills, the presence of this element and its compounds has a deleterious influence on the labor, environmental, maintenance of industrial facilities and EAF dust recycling. In this work, based on the data integration from the literature, industry and on the physical, chemical and thermodynamic properties of the substances involved, a qualitative evaluation of the chlorine path in electric steel plant and its distribution in the different mass flows of the process is made. It was concluded that most of the chlorine entering EAF leaves the system concentrating mainly on process emissions, mostly in EAF dust from the steel plant, in the form of alkaline chlorides
\end{abstract}

Keywords: Chlorine; Electric steelmaking; Recycling; Environment.

Dr., PPG3M, Laboratório de estudos ambientais, LEAmet, UFRGS.

Dr-Ing., PPG3M, Núcleo de termod. computacional para a metalurgia, NTCm, UFRGS.

Dr-Ing., PPG3M, Laboratório de siderurgia, LASID, UFRGS. 


\section{INTRODUÇÃO}

\subsection{0 cloro e o processo de aciaria elétrica}

A aciaria elétrica é o processo de fabricação de aço mais empregado pelas usinas semi-integradas ou "mini-mills". O procedimento compreende as etapas de carregamento, fusão, refino primário, refino secundário e ajuste de composição, seguido do lingotamento. As três primeiras etapas ocorrem no forno elétrico a arco, FEA. Após, o aço fundido é transferido para o forno panela, FP, onde a composição final é ajustada, antes do lingotamento. Apesar de existirem tecnologias onde ocorre o carregamento contínuo do FEA [1], a maioria das usinas opera de modo descontínuo, e a carga é introduzida no FEA com auxílio de transportadores chamados de cestas ou "cestões", providos de um sistema de abertura na sua parte inferior para liberação da carga. Nestes sistemas, o FEA opera em batelada, sendo em geral utilizados dois carregamentos para cada corrida, com um ciclo que inclui a abertura do forno, carregamento das matérias-primas, fechamento do forno, fusão, refino, vazamento e reinício em aproximadamente uma hora.

Durante o carregamento e operação do FEA ocorrem emissões, constituídas de gases e particulados, estes denominados pó de aciaria elétrica, PAE. A ocorrência destas emissões e poeiras é inevitável e é uma característica do processo, demandando recursos para sua gestão devido ao impacto ambiental que ocasionam.

O principal tipo de carga metálica utilizada na aciaria elétrica é a sucata ferrosa, em geral acompanhada de percentuais variáveis de ferro-gusa e escorificantes. As sucatas ferrosas caracterizam-se como uma matéria-prima que apresenta grande variação, em função da qualidade e diversidade dos objetos/materiais presentes, sendo relevante em alguns tipos de sucatas a presença de metais não ferrosos e elementos de liga associados ao aço; impurezas presentes em camadas superficiais, como finos recobrimentos de metais não ferrosos ( $\mathrm{Zn}, \mathrm{Sn}$ ) e películas de pintura e polímeros, principalmente na sucata de obsolescência [2].

O cloro no processo de aciaria elétrica tem sua principal fonte nas contaminações de origem orgânica presentes nas matérias-primas usualmente empregadas, principalmente na sucata [3]. Os níveis de cloro atualmente encontrados trazem poucas interferências na fabricação do aço em si, através do uso do FEA, considerando uma visão de produto. Entretanto, há aspectos colaterais da presença do cloro, sendo talvez de maior importância a questão ambiental. Este fato está relacionado às características do processo de aciaria elétrica, onde, devido a alta temperatura, ocorrem reações de pirólise da matéria orgânica, seguido de combustão e reações de síntese, onde moléculas orgânicas são produzidas (VOCs) ${ }^{1}$ e, após, são destruídas no interior do FEA.

Por outro lado, uma parcela destas moléculas pode escapar dos limites do FEA, mas, o sistema de pós-combustão dos gases e de exaustão/abatimento de poeiras também possui a importante função de completar a destruição destes compostos, principalmente dioxinas (PCDDs) e furanos (PCDFs), por causa dos efeitos deletérios que pequenas quantidades deles provocam no homem e em organismos vivos [4]. No Brasil, o limite para estes compostos em emissões de sistemas para tratamento térmico de resíduos é da ordem de $0,5 \mathrm{ng} / \mathrm{Nm}^{3}$, expresso em TEQ - Toxicidade Equivalente [5]. Paralelamente, a decomposição térmica de

\footnotetext{
${ }^{1}$ VOC - Volatile Organic Compounds.
} 
compostos orgânicos que contêm cloro gera ácido clorídrico $(\mathrm{HCl})$, que exerce marcada influência nos processos corrosivos das instalações industriais. Outro impacto indireto é o acúmulo de cloro nas poeiras, o que prejudica seu tratamento e reciclagem $[6,7]$.

\subsection{O controle das emissões e do cloro no processo de aciaria elétrica}

As emissões do FEA, originadas das etapas de fusão e refino, são classificadas de primárias e as emissões provenientes de outras fontes, como as que ocorrem durante os períodos de carregamento e vazamento, são denominadas de secundárias [8]. Os gases tipicamente gerados no processo são $\mathrm{H}_{2}, \mathrm{CO}$ e $\mathrm{CO}_{2}$, sendo acompanhados por outros, provenientes da atmosfera, principalmente nitrogênio e oxigênio, e, em menores quantidades, por VOCs, compostos inorgânicos de cloro $\left(\mathrm{HCl}, \mathrm{Cl}_{2}\right), \mathrm{SO}_{x}$ e $\mathrm{NO}_{x}$ [9]. Para evitar a dispersão dos materiais particulados e dos gases originados da operação do FEA no ambiente de trabalho da usina, e posteriormente para a atmosfera, é instalado um sistema de retenção de particulados e controle de emissões, o qual pode operar através de várias técnicas [10]. Este sistema se responsabiliza por carrear as poeiras, juntamente com os gases gerados no processo, para uma instalação de abatimento de poeiras.

Modernamente, uma configuração bastante empregada é o tratamento conjunto das emissões primárias e secundárias. Isto é feito de modo a utilizar o grande volume de ar capturado juntamente com as emissões secundárias, em temperaturas mais baixas $\left(\sim 100^{\circ} \mathrm{C}\right)$. Isto é feito para auxiliar na redução da temperatura global dos gases que saem da câmara de pós-combustão, de modo a atingir um nível viável para a utilização de sistemas de despoeiramento à seco. A temperatura dos gases provenientes das emissões primárias pode variar amplamente em função da etapa do processo que lhes deu origem, além da energia adicionada pela combustão. Estes gases atingem temperaturas entre 400 a $600^{\circ} \mathrm{C}$ no início do carregamento e fusão do primeiro cestão, podendo atingir a temperatura de 1500 a $1600^{\circ} \mathrm{C}$ no período de oxidação intensiva do banho [11]. Segundo Toulouevski e Zinurov [11] temperaturas altas na câmara de pós-combustão $\left(T>1250^{\circ} \mathrm{C}\right)$, seguido de um rápido resfriamento, possibilitam a destruição das dioxinas e furanos e a inibição de sua formação secundária.

As poeiras e gases gerados na operação do FEA saem através de uma abertura lateral na tampa, denominada "quarto furo", sendo encaminhados juntamente com ar adicional aspirado para a câmara de combustão. Após, o fluxo de gases e poeiras passa por um conduto refrigerado à água que tem a função de reduzir a temperatura destas emissões antes de ingressar no sistema de coleta de poeiras propriamente dito. A corrente total das emissões (sistemas primário e secundário) é então encaminhada para a "casa dos filtros", onde são retidas as poeiras e os gases são encaminhados para a atmosfera. As emissões gasosas do processo de aciaria elétrica são parte determinante da constituição do ambiente termodinâmico de formação das poeiras de aciaria e dos compostos de cloro existentes na fase gasosa e condensados (incorporados nas poeiras).

No diagrama da Figura 1 pode ser visualizado um esquema genérico de tratamento de gases oriundos do FEA, sendo apontadas temperaturas máximas que podem ser observadas em pontos específicos da instalação, de acordo com valores indicados por Nakayama e Kubo [9]. 


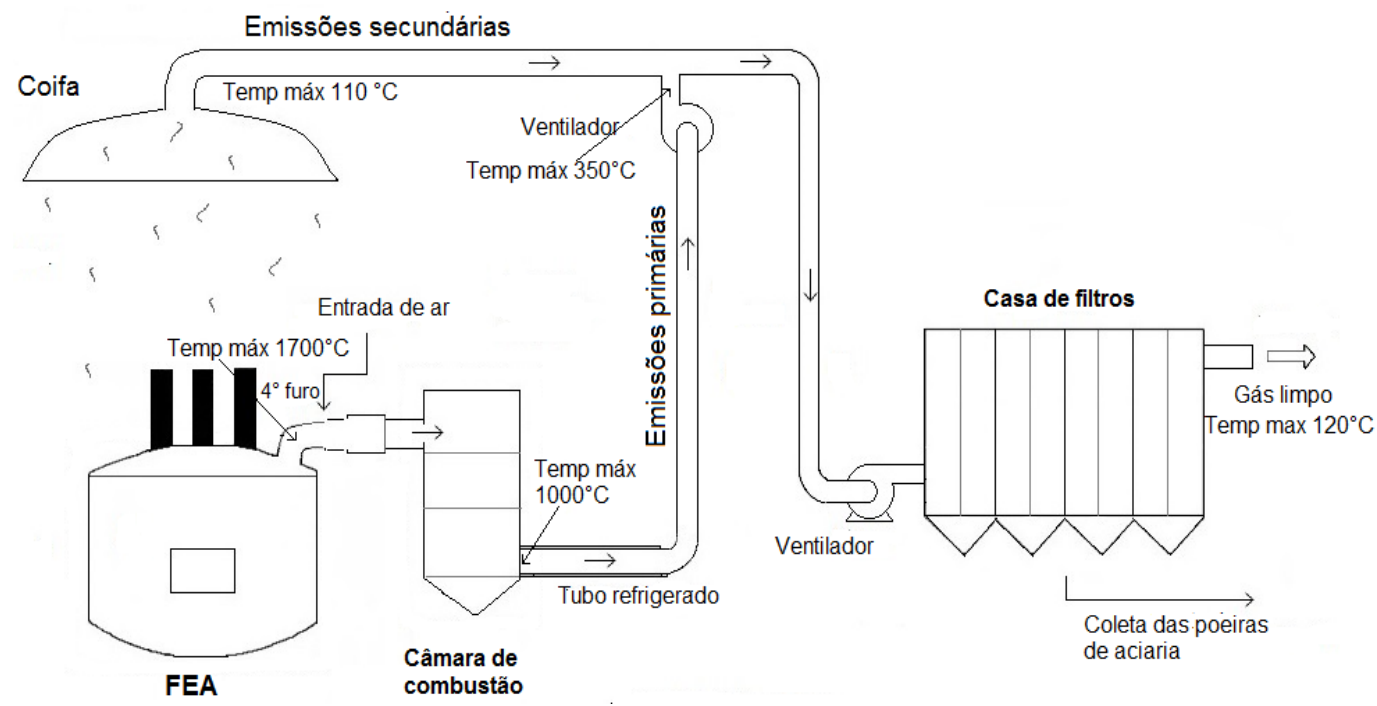

Figura 1. Esquema geral simplificado do sistema de tratamento de gases e coleta de particulados. Fonte: do autor, com valores indicados por Nakayama e Kubo [9].

Considerando o sistema usual de tratamento de gases adotado pelas aciarias elétricas, buscou-se neste estudo elaborar uma descrição qualitativa da passagem do cloro pelo processo de aciaria elétrica que contribua para o entendimento das principais influências deste processo na formação dos compostos de cloro encontrados nas poeiras e nos gases de exaustão.

\section{MATERIAIS E MÉTODOS}

A descrição da passagem do cloro na aciaria elétrica tem foco na formação dos compostos inorgânicos contendo cloro e se baseia na integração de dados disponíveis na literatura, da indústria e de propriedades físicas, químicas e termodinâmicas das substâncias envolvidas, tais como dados analíticos das poeiras, escórias, emissões gasosas e a dinâmica do processo de aciaria elétrica. Nesta análise, a fabricação do aço pelo FEA foi dividida em etapas: (i) preparação, (ii) refino e (iii) pós-combustão de gases e abatimento de particulados, identificando os principais aspectos de cada etapa que contribuem na formação de compostos de cloro. Para identificação dos compostos solúveis de cloro existentes nas poeiras foi preparado um extrato salino que foi posteriormente analisado por difração de raios $\mathrm{X}$. Considerando a pequena parcela de cloro associada a determinados compostos, em relação ao total que ingressa no processo, a possível geração de dioxinas, furanos e outros compostos orgânicos de cloro gerados no processo de aciaria elétrica não é abordada nesta análise.

\section{RESULTADOS E DISCUSSÃO}

\subsection{Aspectos gerais da passagem do cloro pela aciaria elétrica}

A passagem do cloro pelo processo de aciaria elétrica se dá com a transformação das espécies químicas que o contém ao longo das diversas condições que se estabelecem durante o processamento das matérias-primas e a extração das emissões atmosféricas (gases e particulados). Apesar de que diversas práticas operacionais já se encontram consolidadas em grande parte das usinas, estes ambientes (sob o ponto de vista da termodinâmica) são variáveis, em 
dependência de cada etapa do processo, podendo também sofrer alterações em função das condições específicas de processamento de cada instalação.

O cloro é sabidamente um elemento muito reativo, sendo digno de nota o poder de mobilização que apresenta em relação aos metais, principalmente alcalinos, formando com eles cloretos ${ }^{2}$. Em razão disto, existe o potencial do cloro interferir nos equilíbrios termodinâmicos que tendem a formar as espécies químicas comumente encontradas nas poeiras e nos gases, as quais são modificadas pela passagem no sistema de exaustão e despoeiramento. Os cloretos metálicos, alguns deles estáveis em alta temperatura, principalmente de metais alcalinos e alcalinoterrosos, são em geral voláteis nas temperaturas comumente encontradas na aciaria elétrica. Na Tabela 1 podem ser visualizados dados referentes aos pontos de fusão e ebulição, a 1 atm, de alguns deles.

Tabela 1. Pontos de fusão e ebulição a 1 atm de alguns cloretos inorgânicos $\left({ }^{\circ} \mathrm{C}\right)$

\begin{tabular}{|c|c|c|}
\hline Espécie química & Ponto de fusão $\left({ }^{\circ} \mathrm{C}\right)$ & Ponto de ebulição $\left({ }^{\circ} \mathrm{C}\right)$ \\
\hline $\mathrm{PbCl}_{2}$ & 501 & 954 \\
\hline $\mathrm{CaCl}_{2}$ & 772 & $>1600$ \\
\hline $\mathrm{MgCl}_{2}$ & 712 & 1412 \\
\hline $\mathrm{KCl}$ & 790 & 1500 \\
\hline $\mathrm{NaCl}$ & 800,4 & 1413 \\
\hline $\mathrm{ZnCl}_{2}$ & 283 & 732 \\
\hline
\end{tabular}

Fonte: Perry \& Chilton [12].

Sabe-se, entretanto, que a tendência de formação de uma determinada espécie química num sistema termodinâmico constituído por vários elementos, como é o caso da aciaria elétrica, depende principalmente dos seguintes fatores: (i) atividade de cada elemento; (ii) temperatura; (iii) maior estabilidade relativa da espécie química considerada em relação aos outros compostos de mesma natureza possíveis de serem formados na mesma condição ( $\Delta \mathrm{G}^{\circ}$ de formação); (iv) as possíveis mudanças de composição do sistema ao longo do tempo e (v) condições cinéticas mais ou menos favoráveis para se atingir o equilíbrio.

Pode-se inferir então que as mudanças nas espécies químicas portadoras de cloro na aciaria elétrica vão depender em grande parte do percentual relativo de cloro que entra junto com a carga no processo, da composição da carga em termos dos demais constituintes, das propriedades dos compostos formados e das demais condições físicas e químicas, e cinéticas imperantes em cada etapa do processo. Diagramas termodinâmicos específicos mostram a relativa estabilidade de cloretos metálicos em situações possíveis de serem encontradas no processo de aciaria elétrica (altas temperaturas), e de óxidos metálicos em equilíbrio com o cloro, mostrando que, em geral, os cloretos de metais alcalinos e alcalino-terrosos encontram-se entre os compostos mais estáveis (menor $\Delta \mathrm{G}^{\circ}$ de formação), numa situação teórica de equilíbrio termodinâmico.

A passagem do cloro pelo processo de aciaria elétrica inicia-se pelo carregamento do FEA com as matérias-primas (sucatas, cales, etc.). Durante o processamento são geradas três principais correntes de massa de saída: (a) aço

2 A reatividade do cloro é utilizada em vários processos metalúrgicos, como por exemplo, na metalurgia extrativa do titânio e do zircônio. Estudos também têm sido efetuados buscando-se a recuperação de metais das poeiras de aciaria (zinco e chumbo) através de cloração seletiva. 
líquido, (b) escórias e (c) emissões atmosféricas, compostas de gases e poeiras. Para uma avaliação preliminar qualitativa da presença do cloro nas diversas correntes do processo são feitas as seguintes considerações:

a) na operação normal do FEA, as correntes correspondentes ao aço líquido e à escória somente deixam o equipamento ao final de cada corrida, sob uma temperatura próxima aos $1650^{\circ} \mathrm{C}$;

b) as emissões, ao contrário, são geradas em todas as fases de processamento;

c) os compostos mais simples de cloro $\left(\mathrm{HCl}, \mathrm{Cl}_{2}\right)$ encontram-se no estado gasoso, mesmo na temperatura ambiente; já os cloretos com maior probabilidade de serem formados possuem em sua maioria pontos de fusão e ebulição abaixo ou próximos da temperatura mais alta de processo (Tabela 1);

d) o cloro é muito reativo, portanto é um gás que em princípio não irá se dissolver sem reagir no banho metálico; os eventuais cloretos inorgânicos formados a partir de reações do cloro (ou $\mathrm{HCl}$ ) com metais existentes na carga são muito pouco solúveis no banho metálico [13] e possuem densidade menor;

e) considerando todas as etapas do processo e sistema de controle de emissões, somente uma pequena parte do cloro formará compostos organo-clorados;

f) o tempo total de uma corrida no FEA (carregamentos-fusão-refino primáriovazamento) para um grande número de instalações é de cerca de 1 hora.

Inicialmente, pode-se dizer que há carência de estudos abrangentes sobre a distribuição do cloro nas diversas correntes de massa do processo de aciaria elétrica. A maioria dos estudos já realizados com foco no cloro concentra-se na formação/destruição de compostos deletérios ao ambiente laboral, ao meio ambiente e às instalações (PCDD, PCDF, VOCs, HCl, etc.). Por exemplo, para a escória proveniente da aciaria elétrica, há poucos trabalhos cujos dados de caracterização incluem o cloro, salvo informações relacionadas à lixiviação, para verificação do atendimento de parâmetros ambientais. Na tabela 2 encontram-se alguns dados referentes ao teor de cloro em escórias de aciaria elétrica e de alto-forno, verificando-se que em geral as escórias apresentam baixas concentrações de cloro.

Tabela 2. Dados de caracterização de cloretos $\left(\mathrm{Cl}^{-}\right)$em escórias de aciaria (\% em massa).

\begin{tabular}{lccccc}
\hline Referência & $\begin{array}{c}\text { Sófilic et al. } \\
(2010)\end{array}$ & $\begin{array}{c}\text { Araujo } \\
(2008)\end{array}$ & $\begin{array}{c}\text { Sas et al. } \\
(2015)\end{array}$ & $\begin{array}{c}\text { Pacheco } \\
(2006)\end{array}$ & $\begin{array}{c}\text { Rossa Junior } \\
(2009)\end{array}$ \\
\hline Tipo escória & FEA & FEA & FEA/alto-forno & FEA & Alto-forno \\
$\% \mathrm{Cl}^{-}$ & 0,02 & 0,02 & 0,003 & Traços* $^{*}$ & Entre 0,0 e 0,08 \\
\hline
\end{tabular}

${ }^{*}$ traços $<0,1 \%$

Outros dados da literatura de processos relacionados, fazem referência à presença de cloro nas escórias. Por exemplo, para o processo Waelz de reciclagem de poeiras de aciaria, Beyzavi e Mattich [14] relatam que cerca de 95\% do cloro que entra no processo é volatilizado nas condições redutoras vigentes sendo que o restante do cloro permanece na escória, na faixa entre 0,03 e 0,05\% em massa. Madias [15], reporta concentrações de cloro na escória um pouco mais elevadas $(0,1$ - 0,5\% em massa). Complementando, Mager et al.[16] informam que o aumento da basicidade das escórias favore uma redução significativa no cloro livre $(\mathrm{HCl})$ existente nas emissões gasosas, ocorrendo um aumento do cloro retido nas escórias. Estes autores presumem que os componentes básicos da escória (dentre eles o $\mathrm{CaO}$ ) reagem com o cloro existente na corrente gasosa. Pode-se então inferir que, no caso específico do processo Waelz, a temperatura do processo $\left(\sim 1200^{\circ} \mathrm{C}\right)$, a 
composição da carga e da escória e o tempo de residência são fatores que influenciam na distribuição do cloro tanto nas emissões quanto nas escórias.

Para aplicações típicas da siderurgia, pode-se examinar dados de uma extensa pesquisa realizada na busca de um melhor entendimento da passagem do cloro e álcalis no alto-forno [17]. Esta pesquisa, baseada em informações colhidas em instalações especialmente preparadas e industriais, informações obtidas em ensaios laboratoriais, e simulações termodinâmicas, resultou nas seguintes observações de interesse para este trabalho, com relação ao cloro:

a) existe alta afinidade do cloro com os metais alcalinos, principalmente potássio, seguido do sódio, formando cloretos. Estes compostos são muito estáveis e uma vez gerados, têm a tendência a recircular durante o processamento, podendo formar depósitos;

b) a saída do cloro do processo é principalmente pelo gás de topo, pelo fato de não terem sido encontradas quantidades significativas de cloro na escória, nem observadas no metal aquecido; as espécies químicas portadoras de cloro somente podem deixar o alto-forno na forma de gotículas condensadas na superfície das poeiras ( $\mathrm{NaCl}$ e $\mathrm{KCl}$ ), ou como $\mathrm{HCl}$, junto com o gás de topo;

c) em situações de excesso de entrada de cloro, simulações termodinâmicas mostram que, no caso da razão cloro/potássio ser maior que a estequiométrica, ocorre um aumento de $\mathrm{HCl}$ na fase gasosa;

d) análises do gás de topo mostraram que em geral há um excesso de cloro em relação à estequiometria de formação dos cloretos $(\mathrm{KCl}$ e $\mathrm{NaCl})$, significando que a não formação total de cloretos se deve à questões cinéticas ou falta de contato entre os metais alcalinos e o cloro $(\mathrm{HCl})$.

Levando-se em conta as informações anteriormente mencionadas, passa-se à análise da passagem do cloro no processo de aciaria elétrica, verificando-se que é bem mais complexa, já que na maior parte dos casos a operação é descontínua, diferentemente dos processos anteriormente discutidos. Entretanto, há semelhanças entre algumas das condições termodinâmicas existentes, o que pode sugerir uma tendência à geração de compostos similares. Sob este ponto de vista, pode-se visualizar o processo de aciaria elétrica como sendo composto de carregamentos sucessivos e um período de processamento ao final do qual se encerra (lingotamento), reiniciando após um novo ciclo ${ }^{3}$.

De acordo com esta visão, e com objetivo de analisar o trânsito do cloro, deve-se considerar inicialmente a dinâmica do processamento das matérias primas no FEA. Percebe-se que a operação do FEA está dividida em duas etapas principais, com características distintas: (i) preparação e (ii) refino. Há ainda um terceiro fator que atua em sequência à operação do FEA, e que é decorrente do sistema de controle das emissões (pós-combustão de gases e sistemas de controle primário e secundário).

Através de uma análise integrada da literatura ${ }^{4}$, pode-se inferir que estas três circunstâncias formam os principais ambientes que exercem influência tanto na

\footnotetext{
${ }^{3}$ Este sistema de processamento é utilizado na maior parte das aciarias elétricas, com exceção dos processos onde há carregamento contínuo, como o Consteel [1].

${ }^{4}$ A literatura que aborda aspectos do processo de aciaria elétrica é muito ampla. Em geral há referência a aspectos particulares do processo, tais como formação das poeiras [18]; geração de compostos de cloro e dioxinas [3,9,19]; gases gerados no processo [20,21]; sistema de despoeiramento [10]; visão geral do processo [11], somente para exemplificar.
} 
formação dos compostos de cloro quanto das poeiras, a partir de uma determinada composição da carga que ingressa no processo de aciaria elétrica. Uma descrição das etapas de fabricação do aço pelo FEA, com foco no trânsito do cloro, é apresentada nos tópicos a seguir descritos.

\subsection{Etapa de preparação}

A etapa de preparação compreende as subetapas de carregamento e fusão, as quais são usualmente repetidas de duas a três vezes dentro de uma mesma corrida. A preparação se caracteriza pela intermitência e certa irregularidade, função das condições particulares de operação e, fundamentalmente, da composição da carga (sucatas, cales, aditivos, etc.). No intervalo entre corridas ou carregamentos, é feita a abertura do forno pelo basculamento mecânico da abóbada, permitindo a descarga do cestão no interior do FEA. Durante o carregamento, em função do calor residual da corrida anterior, é comum observar-se a formação de labaredas e fumos, decorrentes da pirólise dos compostos orgânicos aderidos à sucata no momento em que a carga sofre o choque térmico do contato com as paredes do FEA. Parte dos gases combustíveis formados pela pirólise entra em combustão com 0 ar circundante e há formação de particulados. Estas emissões são capturadas pelo sistema secundário de controle das emissões (coifa) e posteriormente misturadas com as que saem da operação propriamente dita do FEA (captadas pelo sistema primário).

Após o carregamento, há o fechamento da abóboda e a introdução dos eletrodos, iniciando-se a fusão da carga do cestão. Durante o carregamento do forno e a fusão da carga, as substâncias orgânicas contendo o cloro são destruídas e o cloro é liberado principalmente na forma de $\mathrm{HCl}$. Imediatamente, em função da composição da atmosfera e da temperatura, o cloro passa a reagir, recombinandose e formando compostos clorados (orgânicos e inorgânicos).

$\mathrm{Na}$ Figura 2 pode ser visualizado um panorama geral do funcionamento do FEA logo após o carregamento e o fechamento da abóboda, com a carga ainda não completamente fundida. Nesta etapa, além dos gases $\mathrm{CO}, \mathrm{CO}_{2}, \mathrm{H}_{2}$ e VOCs, podem ser observadas as maiores concentrações de $\mathrm{HCl}$, as quais podem atingir valores próximos de 1000 ppm no início da fase de fusão [9].

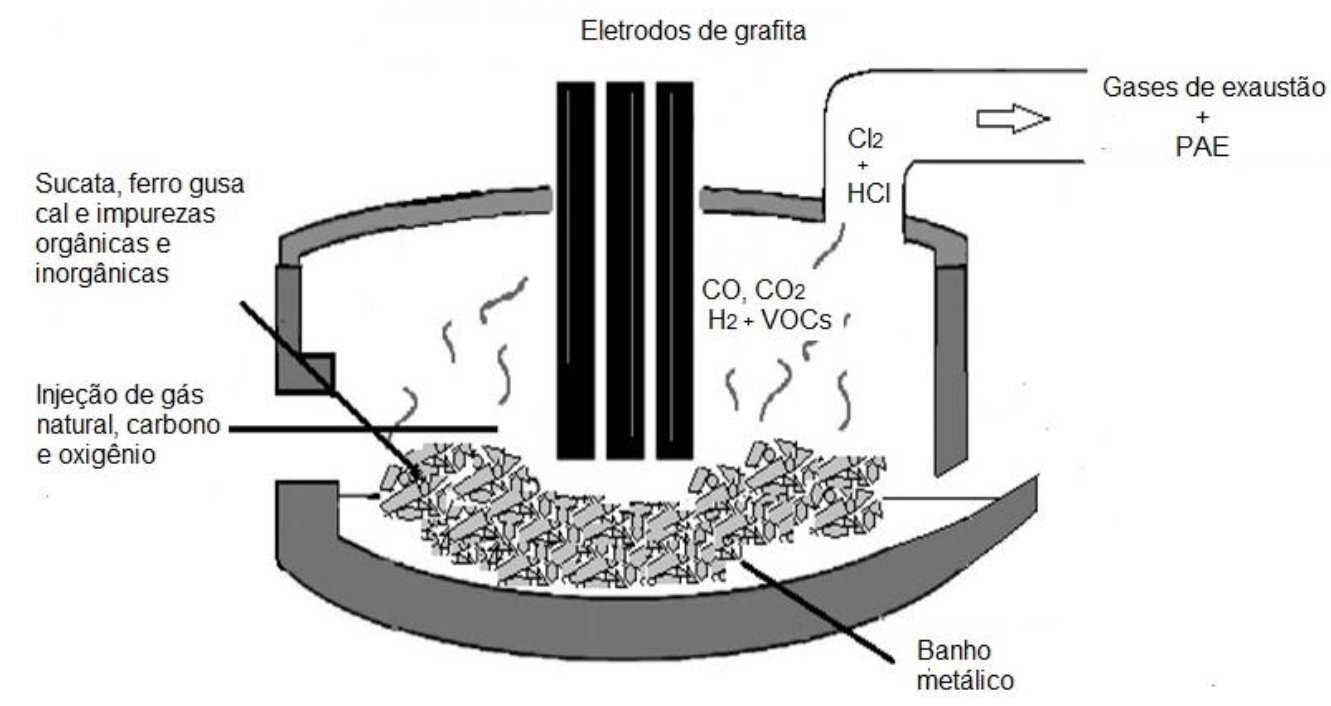

Figura 2. Panorama geral do início da fusão da carga no FEA, após a conclusão do carregamento. Fonte: do autor, adaptado de concepção original de Guézennec et al. [18]. 
Sabe-se também que nem todo cloro que entra no processo forma compostos clorados condensados no resfriamento das emissões (cloretos inorgânicos e compostos organoclorados). Uma parte transita por todo o processo e permanece nas emissões gasosas como $\mathrm{HCl}^{5}$.

O pico de concentração de cloro $(\mathrm{HCl})$ na fase gasosa indica que a pirólise dos compostos portadores de cloro ocorre principalmente nesta etapa. Esta circunstância pode significar que nem todo o cloro encontra-se em equilíbrio termodinâmico com os demais constituintes da carga, tanto por questões cinéticas quanto por menor contato químico (rápida exaustão dos gases pelo quarto furo), sendo esta a provável razão para a ocorrência destes picos.

\subsection{Etapa de refino}

A etapa do refino compreende o ajuste da composição do aço, especialmente do carbono e fósforo, e é conhecida por "refino primário ou oxidante". Em comparação com a etapa de preparação, se caracteriza por uma maior regularidade, fruto da homogeneização da totalidade da carga em um banho metálico único e das características do processo de refino aplicado. Nesta fase ocorre um maior desprendimento de $\mathrm{CO}$ a partir da oxidação do carbono do banho metálico pelo oxigênio injetado e a temperatura encontra-se em patamar elevado $\left(\sim 1650^{\circ} \mathrm{C}\right)$. Nestas condições pode-se considerar que já não há compostos orgânicos de cloro (inclusive $\mathrm{HCl}$ ) sendo gerados no interior do FEA. Entretanto, é possível supor que ainda pode ocorrer pequena entrada de cloro através do carbono injetado. Além disso, compostos inorgânicos de cloro (cloretos metálicos) já existentes na carga (ou formados em razão de reações químicas) e que ainda não foram volatilizados na etapa anterior, são vaporizados em grande parte nesta etapa, passando para as emissões do processo. Segundo o mecanismo proposto por Guézennec [18], a geração de bolhas de CO no banho metálico é o fator principal responsável pela fração ferrosa das poeiras, as quais são arrastadas para a câmara de pós combustão e sistema de abatimento juntamente com os cloretos volatilizados.

\subsection{Etapa de pós combustão e abatimento de particulados}

Nesta etapa ocorre inicialmente a queima dos gases combustíveis que deixam o FEA com excesso de ar, caracterizando um ambiente oxidante em alta temperatura por onde transitam as emissões atmosféricas (gases e sólidos) originadas do FEA $\left(\sim 1000^{\circ} \mathrm{C}\right)$. Nesta atmosfera podem ocorrer reações químicas que consolidam a formação das poeiras e compostos de cloro associados, e eliminam as dioxinas, furanos e organoclorados, liberando o cloro, que tanto pode permanecer nos gases quanto reagir quimicamente formando novos compostos. Estas emissões sofrem um contínuo resfriamento pela passagem nos dutos até a casa dos filtros, onde particulados e material condensado são retidos. Após, os gases são liberados para a atmosfera, podendo existir acréscimo de compostos de cloro provenientes das emissões secundárias que se juntam com a as emissões primárias (Figura 1). Ao final do trânsito pelo processo, pode-se dizer que o cloro que passou às emissões se distribui entre a fase gasosa $\left(\mathrm{HCl}, \mathrm{Cl}_{2}\right)$ e as fases condensadas (cloretos). Compostos organoclorados em pequena proporção também

\footnotetext{
${ }^{5}$ Este composto pode ser detectado mediante análise dos gases de exaustão final do processo (saída da casa de filtros) através da metodologia USEPA Method 026A .
} 
podem se apresentar tanto nos gases quanto como substâncias condensadas nas poeiras, dependendo das suas propriedades e condições de operação de cada usina.

A descrição das etapas por onde passa o cloro pode ser complementada por uma visão geral do comportamento deste elemento nas condições do processo de aciaria elétrica. Esta análise, com as limitações pertinentes a uma avaliação teórica de um processo complexo, baseia-se em trabalhos já publicados [22,23]. Através destes estudos termodinâmicos, foi determinado que, em situação de completo equilíbrio entre componentes da carga (sistema constituído de $\mathrm{Fe}, \mathrm{O}, \mathrm{Zn}, \mathrm{Cl}, \mathrm{H}, \mathrm{C}$, $\mathrm{Na}, \mathrm{K}$ e $\mathrm{Pb}$ ), nas condições do processo da aciaria elétrica ( $\mathrm{T}$ inicial $\sim 1600^{\circ} \mathrm{C}$, decaindo até $\left.100^{\circ} \mathrm{C}\right)$, em atmosfera de composição próxima à do ar $\left(\sim 78 \%\right.$ vol $\mathrm{N}_{2}$, $21 \% \mathrm{O}_{2}$ ), os metais alcalinos ( $\mathrm{Na}$ e $\mathrm{K}$ ) formam cloretos $(\mathrm{NaCl}$ e $\mathrm{KCl}$ ). Estes compostos, dependendo da temperatura e da etapa do processo, podem estar na tanto na fase gasosa quanto na fase condensada $\left(T<800^{\circ} \mathrm{C}\right)$, junto às poeiras. Cloretos de chumbo e zinco também podem ser formados, dependendo da quantidade de cloro existente.

Confirmando a tendência de formação de cloretos alcalinos condensados nas poeiras, na Figura 3 é apresentado um difratograma de um extrato salino originado de poeira de aciaria gerada por uma usina siderúrgica semi-integrada, a qual continha originalmente $2 \%$ em massa de cloro. Este extrato apresentou $45,8 \%$ em massa de cloro e os picos mais relevantes mostram a presença majoritária de cloretos de sódio e potássio [24].

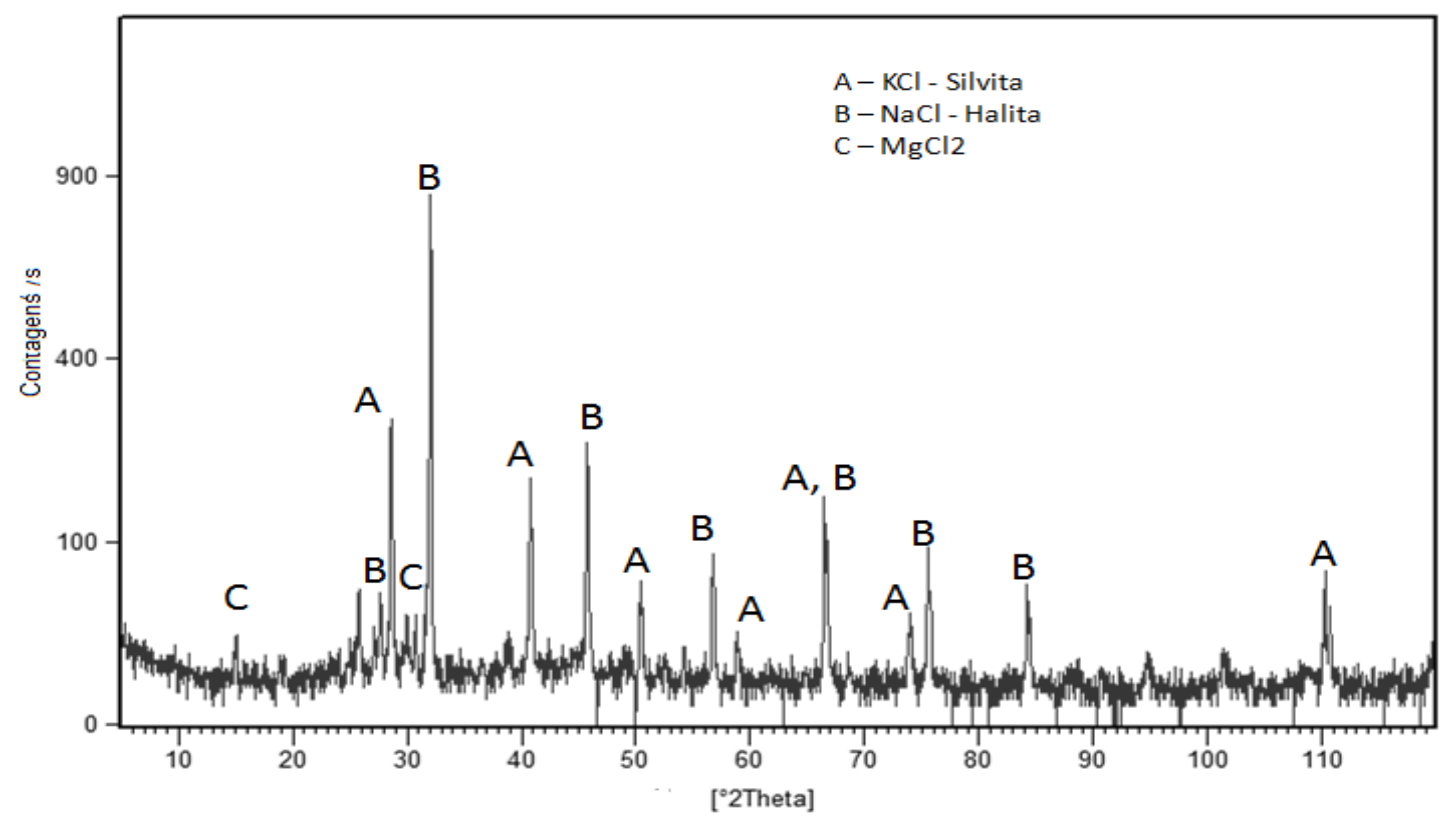

Figura 3. Difratograma do extrato salino do PAE da usina AECSS.

Fonte: Buzin [24]

\section{CONCLUSÃO}

Com base nas informações anteriormente expostas, nos dados da distribuição do cloro em poeiras de aciaria [7], e na baixa concentração de cloro existente nas escórias, pode-se concluir que a maior parte do cloro que entra no processo de aciaria elétrica sai com as emissões atmosféricas, tanto na forma de cloretos condensados nas poeiras quanto nos gases, na forma de $\mathrm{HCl} \mathrm{e} \mathrm{Cl}_{2}$. 
É importante salientar que este estudo qualitativo mostra somente uma tendência do cloro acumular-se preferencialmente nas emissões (poeiras e gases) do processo, sendo necessários estudos adicionais acerca dos fenômenos envolvidos e espécies químicas formadas. Ainda, é necessário avaliar a influência da variação da composição da carga e de outros fatores presentes no processo sobre a especiação e distribuição quantitativa de cloro em cada um dos fluxo de massa, com vista ao desenvolvimento de tecnologias que possibilitem o controle do cloro livre $\left(\mathrm{HCl} \mathrm{e} \mathrm{Cl}_{2}\right)$ nas emissões do processo. Considerando que a escória tem uma capacidade limitada de absorção de cloro nas condições de operação da aciaria elétrica, pode-se também inferir que um aumento de cloro na carga tem como consequência direta um aumento do cloro nas emissões atmosféricas (gases e poeiras).

\section{Agradecimentos} pesquisa.

Os autores agradecem à empresa Gerdau S/A pelo apoio dado a esta

\section{REFERÊNCIAS}

1 Memoli F, Ferri MB, Freitas JV. Aumento das Plantas Consteel no Mundo: flexibilidade para a carga continua de gusa liquido e sucata no forno elétrico a arco agora na siderurgia brasileira. Tecnologia em Metalurgia, Materiais e Mineração. 2009; 6(1): 5960.

2 Chatterjee A, Singh R, Pandey B. Metallics for Steelmaking - Production \& Use. New Delhi, India: Allied Publishers Ltd.; 2001.

3 Birat J-P, Arion A, Faral M, Baronnet F, Marquaire, P-M, Rambaut P. Abatement of organic emissions in EAF exhaust flue gas. La Revue de Métallurgie-CIT, 2001; 98 (10): 839-854.

4 Pereira MS. Polychlorinated dibenzo-p-dioxins (PCDD), dibenzofurans (PCDF) and polychlorinated biphenils (PCB): main sources, environmental behavior and risk to man and biota. Quimica Nova. 2004; 27(6): 934-943.

5 Resolução Conama $n^{\circ} 316$, de 29 de outubro de 2002. Dispõe sobre procedimentos e critérios para o funcionamento de sistemas de tratamento térmico de resíduos.

6 Buzin, PJWK, Heck, NC, Vilela, ACF. EAF dust: An overview on the influences of physical, chemical and mineral features in its recycling and waste incorporation routes. Journal of Materials and Research Technology. 2017; 6(2): 194-202.

7 Buzin, PJWK, Heck, NC, Vilela, ACF. A influência da Classificação e beneficiamento da sucata no teor de cloro do pó de aciaria elétrica. In: Associação Brasileira de Metalurgia, Materiais e Mineração. Anais do $72^{\circ}$ Congresso Anual da ABM; 2017; São Paulo, Brazil.

8 Mantovani MC. Comportamento a Frio e a Quente de Pelotas Auto-redutoras de Resíduo de Aciaria Elétrica [dissertação de mestrado]. São Paulo: Escola Politécnica da USP; 1996.

9 Nakayama M, Kubo H. Progress of emission control system in electric arc furnace meltshops. NKK Technical Review. jul 2001 [acesso em 25 jan 2014]; 84. Disponível em http//www.jfe-steel.co.jp/archives /em/nkk_giho/84/03.html,

10 Acosta CD, Reckziegel VN, Vilela ACF, Ribeiro JLD. Assessment of Environmental Practices and Technologies Associated with Electric Arc Furnace (Eaf) and Ladle Refining Furnace (Lf) Baghouse Dust. American Journal of Environmental Engineering, 2012; 2(6): 196-211.

11 Toulouevski YN, Zinurov IY. Innovation in Electric Arc Furnaces. Berlin: SpringerVerlag Berlin Heidelberg; 2013. 
12 Perry $\mathrm{RH}$, Chilton, $\mathrm{CH}$. Manual de Engenharia Química, 5르. Ed. Rio de Janeiro: Editora Guanabara Dois; 1980.

13 Rosenqvist T. Principles of Extractive Metallurgy. Tóquio: MacGraw Hill Kogakusha, Ltda;1974.

14 Beyzavi AL, Mattich C. Operational Practice With the Waelz Kiln and Leaching Plant of TSU in Taiwan. In: Fourth International Symposium on Recycling of Metals and Engineered Materials. The Minerals, Metals \& Materials Society - TMS; october, 22-25, 2000; Pittsburg, Pennsylvania.

15 Madias J. Techologies to Transform Steelmaking Sludge/Dust in byproducts. Palestra proferida na ABM Week, Riocentro, Rio de Janeiro, Brazil: August, $20^{\text {th }} ; 2015$ [acesso em 15 de março de 2016]. Disponível em: https://www.researchgate.net/ publication/282574974_technologies_to_transform_steelmaking_sludge_in_byproducts

16 Mager K, Meurer U, Wirling J. Minimizing Dioxin and Furan Emissions During Zinc Dust Recycle by the Waelz process. JOM. 2003; 55(8):21-25.

17 Lin R, Jahnsen U, Widner S, Burgler T.; Lectard É, Sert, D. et al. Investigations of Chlorine and Alkali Behaviour in the Blast Furnace Slag with Respect to Alkali retention Capacity. Office for Official Publications of the European Communities, report EU/European Commission. 2003; 20586: 338 p.

18 Guézennec AG, Huber JC, Patisson F, Sessiecq P, Birat J-P, Ablitzer D. Dust Formation in Electric Arc Furnace: Birth of the Particles. Powder Technology. 2005; 157: 2-11.

19 Tysklind M, Soderstrom G, Rappe C. PCDD and PCDF Emissions from Scrap Metal Melting Processes at a Steel Mill. Chemosfere. 1989; 19, (1-6): 705-710.

20 Grant MG. Principles and Strategy of EAF Post-combustion. In: 58 ${ }^{\text {th }}$ Electric Furnace Conference; 2000; Orlando,USA.

21 Labiscsak L, Straff Lini G, Corbetta C, Bodino M. Fluydinamics of a Post-combustion Chamber in Electric Arc Steelmaking Plants. WIT Transactions on Modelling and Simulation. 2011 (51).

22 Buzin, PJWK, Heck, NC, Vilela, ACF. EAFD Generation - Thermodynamic Analisys of Fe-Zn-O-Cl-H-C System. In: Associação Brasileira de Metalurgia, Materiais e Mineração. Anais $45^{\text {th }}$ Steelmaking Seminar - International;2014; Porto Alegre-RS, Brazil.

23 Buzin, PJWK, Heck, NC, Vilela, ACF. Thermodynamic Study of EAFD Genesis in the Presence of Chlorine in Electric Arc Furnace. In: Associação Brasileira de Metalurgia, Materiais e Mineração. Anais $69^{\circ}$ Congresso ABM - Internacional;2014; São Paulo, Brasil,.

24 Buzin PJKB. Desenvolvimento de um processo para redução do teor de cloro em pó de aciaria elétrica. [tese de doutorado]. Porto Alegre: Ufrgs, PPG3M, Escola de Engenharia; 2016.. 